\title{
Observatório global de atividade física: monitoramento de uma pandemia do século 21
}

A inatividade física causa mais de cinco milhões de mortes por ano no mundo ${ }^{1}$. Mesmo assim, $1 / 3$ da população adulta e alarmantes $80 \%$ da população adolescen$\mathrm{te}^{2}$ não atingem as recomendações globais de atividade física para a saúde ${ }^{2}$. Tendo em vista sua alta prevalência e seus alarmantes efeitos deletérios sobre a saúde, a inatividade física foi classificada como uma pandemia ${ }^{3}$, com consequências intoleráveis sobre a saúde, o ambiente, a economia e a sociedade como um todo.

Embora o conhecimento científico sobre atividade física venha crescendo exponencialmente nos últimos anos e que uma série de intervenções com comprovada efetividade estejam disponíveis ${ }^{4,5}$, menos atenção vem sendo dada a transformação do conhecimento acumulado em ação, seja no nível local, regional, nacional ou global. Com o objetivo de preencher essa lacuna, em 2012 foi criado um Observatório Global de Atividade Física (http://www.globalphysicalactivityobservatory. $\mathrm{com} /)^{6,7}$. O Observatório é uma entidade afiliada a Sociedade Internacional de Atividade Física e Saúde (http://www.ispah.org) e tem como meta central transformar a abundante informação existente sobre atividade física e saúde em ação, além de monitorar o progresso da pandemia da inatividade física periodicamente.

Um dos produtos centrais do Observatório é a criação de country cards para cada país do mundo. Tais cartões serão lançados de dois em dois anos e sumarizam o status de cada país em relação a pesquisa, vigilância e política na área de atividade física no ano da avaliação (2013, no caso dos primeiros country cards). A expectativa do Observatório é que esses country cards tornem-se ferramentas de avaliação para ajudar os governos, os pesquisadores e a sociedade a melhorar o seu estado de saúde por meio da prática de atividade física ${ }^{7}$. Para cumprir o seu objetivo, os country cards irão sumarizar informações atuais relacionadas com a atividade física, incluindo: existência de inquéritos de base populacional que incluam questões de atividade física; a prevalência de atividade física em adultos; existência de política nacional de atividade física; número de pesquisadores que tiveram pelo menos um artigo publicado; e, também, a partir destes dados, um ranking para mostrar a posição de cada um dos países em relação à contribuição (\%) para a pesquisa global de atividade física.

O processo de criação dos country cards foi longo. Os membros do comitê executivo tiveram as primeiras ideias sobre indicadores e layout, sendo então submetidos (indicadores e layout) a um processo de consulta pública, na qual pesquisadores e outros profissionais de diferentes locais do mundo puderam opinar sobre o conteúdo e o layout dos country cards. Após encerrado esse período, as sugestões foram avaliadas pela equipe do Observatório e uma nova versão dos country cards foi proposta. A primeira versão dos country cards de cada país foi então preparada, e foi iniciada a busca por uma pessoa de contato em cada país. Autores de publicações reconhecidos como líderes na área e representantes de instituições académicas, sociedades de atividade física nacionais e 
internacionais foram convidados para serem contatos de país no Observatório.

Quando a pessoa foi identificada, ela recebia o country card de seu país e podia fazer alterações, correções, ou enviar sugestões gerais. Ao final da revisão, a pessoa de contato era estimulada a traduzir o card para a língua oficial do país e a disseminá-lo livremente assim que os cards forem lançados oficialmente.

Até o presente momento, os cartões já estão prontos para 127 países, sendo o lançamento dos mesmos previsto para mês de dezembro de 2015. Deve-se ressaltar que um card somente é considerado pronto quando suas informações foram conferidas e validadas pela pessoa de contato de cada país. Todos estão disponíveis em inglês e traduções ao idioma original foram feitas naqueles cards cujos contatos estavam interessados em terem o card específico para os seus países, com um total de 26 diferentes idiomas: Árabe, Chinês, Búlgaro, Croata, Checo, Danês, Dinamarquês, Eslovaco, Holandês, Francês, Alemão, Grego, Groelandês, Húngaro, Italiano, Japonês, Lituano, Macedônio, Maori, Nepalês, Polaco, Português, Romeno, Russo, Espanhol, e Sueco. Os 127 países com cards prontos reunem $81 \%$ da população mundial.

Entre as outras atividades principais do Observatório estão identificar contatos em cada país e articular com as redes regionais de atividade física existentes para estabelecer colaboração na promoção de atividade física no mundo. Além disso, o Observatório está liderando a preparação da segunda série de atividade física a ser publicada no Lancet em 2016. Pesquisadores, gestores, sociedades de atividade física nacionais e internacionais estão sendo convidados para fazer parte do Observatório.

O trabalho do Observatório vai além de mostrar os riscos da inatividade física para a saúde. A prioridade é transformar em ação o amplo conhecimento acumulado sobre o assunto e elevar a promoção da atividade física, a vigilância e a política para a sua importância máxima na área da saúde pública.

\section{REFERÊNCIAS}

1. Lee IM, Shiroma EJ, Lobelo F, Puska P, Blair SN, Katzmarzyk PT; Lancet Physical Activity Series Working Group. Effect of physical inactivity on major non-communicable diseases worldwide: an analysis of burden of disease and life expectancy. Lancet. 2012 Jul 21;380(9838):219-29.

2. Hallal PC, Andersen LB, Bull FC, Guthold R, Haskell W, Ekelund U; Lancet Physical Activity Series Working Group. Global physical activity levels: surveillance progress, pitfalls, and prospects. Lancet. 2012 Jul 21;380(9838):247-57. doi: 10.1016/S01406736(12)60646-1. Review. PubMed PMID: 22818937.

3. Kohl HW 3rd, Craig CL, Lambert EV, Inoue S, Alkandari JR, Leetongin G, Kahlmeier S; Lancet Physical Activity Series Working Group. The pandemic of physical inactivity: global action for public health. Lancet. 2012 Jul 21;380(9838):294-305.

4. Heath GW, Parra DC, Sarmiento OL, Andersen LB, Owen N, Goenka S, Montes F, Brownson RC; Lancet Physical Activity Series Working Group. Evidence-based intervention in physical activity: lessons from around the world. Lancet. 2012 Jul 21;380(9838):272-81. doi: 10.1016/S0140-6736(12)60816-2. Review. PubMed PMID: 22818939.

5. Bauman AE, Reis RS, Sallis JF, Wells JC, Loos RJ, Martin BW; Lancet Physical Activity Series Working Group. Correlates of physical activity: why are some people physically active and others not? Lancet. 2012 Jul 21;380(9838):258-71. doi: 10.1016/S01406736(12)60735-1. Review. PubMed PMID: 22818938.

6. Hallal P, Martins R, Ramírez A. The Lancet Physical Activity Observatory: promoting physical activity world wide. Lancet 2014; 384: 471-472.

7. Hallal PC, Ramirez A. The Lancet Physical Activity Observatory: Monitoring a 21st Century Pandemic. Res Exerc Epidemiol 2015; 17(1): 1-5. Japanese Association of Exercise Epidemiology. 